\title{
Labeling of OTC Drugs in India: Dilemma Whether Pharmacy Centred or Patient Centred
}

\author{
Ravi Shankara, Monika Joshi ${ }^{\mathrm{b}}$, Kamla Pathak $^{\mathrm{c}^{*}}$ \\ a Department of Pharmaceutics, Sherwood College of Pharmacy, Barabanki, UP, INDIA. \\ ${ }^{\mathrm{b}}$ Department of Pharmaceutics, Rajiv Academy for Pharmacy, Mathura, U.P, INDIA. \\ 'Department of Pharmaceutics, Pharmacy College Saifai, UPUMS, Saifai, Etawah, Uttar Pradesh, INDIA.
}

\begin{abstract}
Context: OTC medicines are an important component in healthcare, allowing the freedom to the patient to selfmedicate for treating minor, common health problems, at lower costs and with higher time saving. It is very important that the patients have access to sufficient information to make an informed choice for the proper use of these medicines. The label of OTC medicines plays an important role in conveying valuable information to the patient for safe and effective use of OTC. Objective: The study was conducted to evaluate the labelling of OTC drugs in India as per the guidelines of US FDA. Result: The result was not positive as it was found that $59 \%$ of the labels did not disclose even the therapeutic category. There are $87 \%$ labels which do not have any information related to the contraindications and $90 \%$ labels do not enumerate the adverse effects of the medicine. The legibility was very poor comprising only $33 \%$ of total. Conclusion and Practice Implication: The labels were not able to withstand the guidelines of US FDA that may be compromising with the health and safety issues of the patients. The labels should provide all important information and instructions to patient.
\end{abstract}

Key Words: Over the counter medications, USFDA, primary labels, patient package inserts, Indian scenario

\section{INTRODUCTION}

The promotion of consumer involvement in their healthcare is the core principal of health promotion and well being of the society. The best way which is in use in the present scenario is the increased use of OTC drugs rather than prescription drugs. Over the counter (OTC) drugs is one of the self care activities undertaken by individual, family and community intended to promote health and minimize illness. 'OTC Drugs' means drugs legally allowed to be sold 'Over the Counter', i.e. without the prescription of a Registered Medical Practitioner. ${ }^{2}$ OTC drugs plays vital role in healthcare system. A huge part of population rely on OTC for the treatment of common ailments like headache, cold, fever, and cough, indigestion, flu and dermatitis. Therefore, wide safety margin must be established for the OTC drugs. OTC product benefits must outweigh the risk and the chances of misuse of it should be low. ${ }^{3}$ Individuals can directly be involved in their healthcare by increasing purchase of OTC rather than prescribed drugs. ${ }^{4}$ The switching of drugs from prescription to OTC has increased worldwide. Moving trend from prescription to non prescription medications saves the time and also reduces cost as it is cheaper for patients to purchase OTC rather than file a prescription. ${ }^{5}$ In 1996 Food and drug administration (FDA) approved the $\mathrm{Rx}$ to OTC switch of Nicotine patch and gum for the one who want to get out of cigarette addition but don't want to visit a doctor. ${ }^{6}$ There have been a number of prescriptions to OTC switches in the recent past which is documented in table $1 .^{7}$ Non-steroidal antiinflammatory drugs (NSAIDs) like aspirin and paracetamol are the most commonly used OTC medications. ${ }^{8}$ Popularity of OTC drugs in India had risen promptly. As per OTC market size, India ranks $11^{\text {th }}$ as result of high growth rate of OTC market over
DOI: 10.5530/ijopp.9.3.12

Address for correspondence: Dr. Kamla Pathak, Professor and Head, Department of Pharmaceutics, Pharmacy College Saifai, Uttar Pradesh University of Medical Sciences, Saifai, Etawah 206130

Uttar Pradesh,INDIA. Ph.no: 09897612318

Email: kamlapathak5@gmail. com

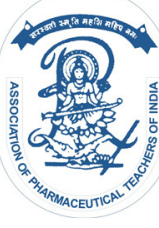

www.ijopp.org 
Table 1: List of drugs switched from $\mathrm{Rx}$ to OTC switch in the recent past years

\begin{tabular}{cccc} 
Name of drug & Active ingredient & Therapeutic indication & Approval date \\
\hline Oxytrol for women & Oxybutynin & Overactive bladder & 25 Jan, 2013 \\
Nasacort Allergy 24HR (nasal spray) & Triamcinolone acetonide & Allergic rhinitis & 11 Oct, 2013 \\
Allegra & Fexofenadine HCl & Antihistamine & 25 Jan, 2011 \\
Prevacid 24 HR & Lansoprazole & Acid reducer/PPI & $18 \mathrm{May}, 2009$ \\
Zegerid OTC & Omeprazole & Acid reducer/PPI & 12 Jan, 2009 \\
Zyrtec allergy and Zyrtec hives relief & Cetrizine HCl & Antihistamine & 16 Nov, 2007 \\
syrup and chewable tablet for children & & & 24 July, 2006 \\
Lamisil Derm gel & Terbinafine & Topical Antifungal & 10 June, 2006 \\
Miralax & Polyethylene glycol 3350 & Laxative &
\end{tabular}

Table 2: Labeling requirements of OTC medications as per FDA and Drug and Cosmetics Act 1940 of India

\begin{tabular}{|c|c|}
\hline As per FDA & As per drug and cosmetic rules (1945) \\
\hline Active ingredient in each dosage unit & Generic and trade name \\
\hline Appropriate precaution for use and special warning & Net contents and content of active ingredient \\
\hline Dosage instructions & Batch number \\
\hline \multicolumn{2}{|l|}{ Interactions } \\
\hline Warnings & $\begin{array}{c}\text { Name and address of manufacturer including manufacturer } \\
\text { license number. }\end{array}$ \\
\hline Adverse effects & Manufacture and expiry date. \\
\hline Directions for use & Maximum retail price \\
\hline
\end{tabular}

past eight years. Current data indicates Indian OTC market to represent $\$ 1,773$ million with a share of $23 \%$ as demonstrated by figure 1.' In India manufacture, purchase, sale of drug is regulated by Drug and cosmetic act 1940 and rules 1945. In India there is no judicial recognition for OTC drugs. The drug included in the schedule $\mathrm{H}$ and $\mathrm{X}$ of drug and cosmetic act are termed as prescription drugs. For the drug listed in schedule $G$ of drug and cosmetic act (1940) no prescription is require but the following mandatory text must be mentioned in the label: "caution: It is dangerous to take this medicine except under medical supervision. ${ }^{10}$ In India and most of the underdeveloped countries all the drugs which are non-prescription are easily available for over the counter sale. The commonly used OTC drugs mainly belong to classes of NSAIDS, anti-allergic, vitamins and supplements, gastrointestinal and medicated dermatological products (Figure 2). The drugs whose stocks are maintained at home, most of the times include antacids, anti flatulent, drugs for headache and loose motion.

OTC drugs are easily accessible and are used for the treatment of minor illness. Although OTC medicines are supposed to be relatively safe, readily available and consumed by patients without physicians consent, it is very important that the patients have the access to clear and broad information to make an informed choice of proper selection of medicine and their fruitful use. It is very important to recognize that even OTC medicines can cause unwanted side effects if not properly used. ${ }^{11}$

The information provided by the label and patient package insert act as a major source of knowledge for the patients regarding various issues for safe and effective use of the medication. The label should provide all the information as the patient has to take it without the consult of the physician. Therefore label is of primary importance as it conveys important drug information to the consumers. The label provides basic information about the drug to the patient like drug name, use, dosage, directions, etc. Additional information of the drug like its pharmacokinetics, pharmacodynamics, adverse effect, indications, risk and benefits are provided through package insert, a FDA approved document dispensed with some drugs. ${ }^{12}$ The information given to the consumers using labels and patient package inserts helps in gaining information regarding safe use of medicine and preventing medication errors and drug abuse. The label must be clear, properly readable by patients and should provide sufficient information to the patients. ${ }^{13}$ A standard format to make drug information clear, simple and readable on label of OTC drugs was proposed by FDA in 1997. The label of a drug in India should confirm the specifications as per drug and cosmetic rule 95 of drug and cosmetic act. The labeling requirement as per drug and 


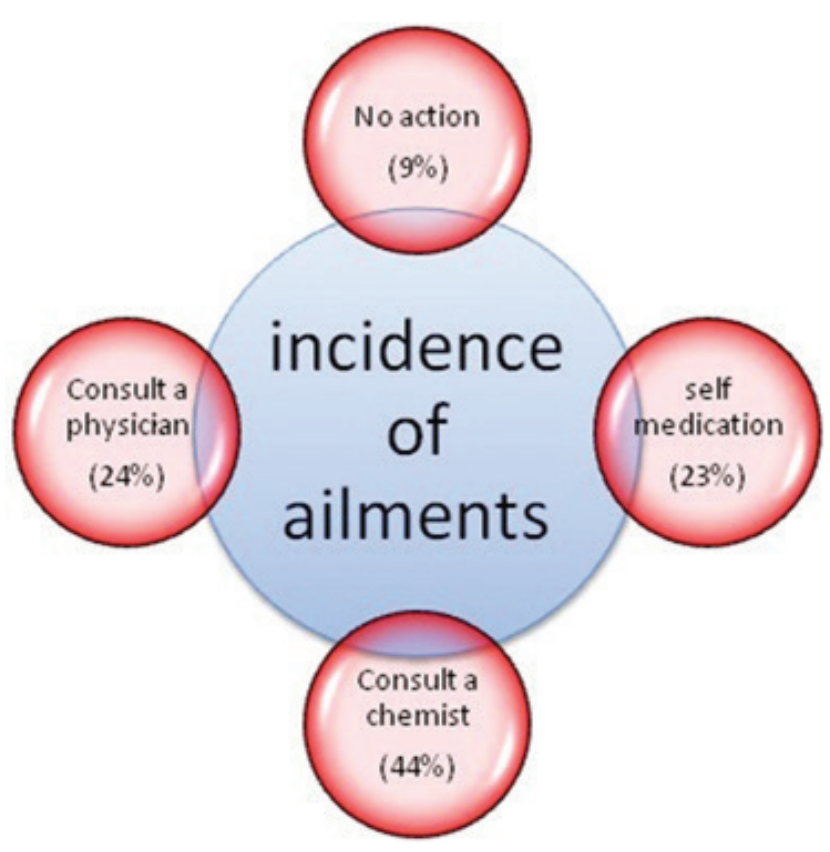

Figure 1: Current status of OTC drugs in the Indian market

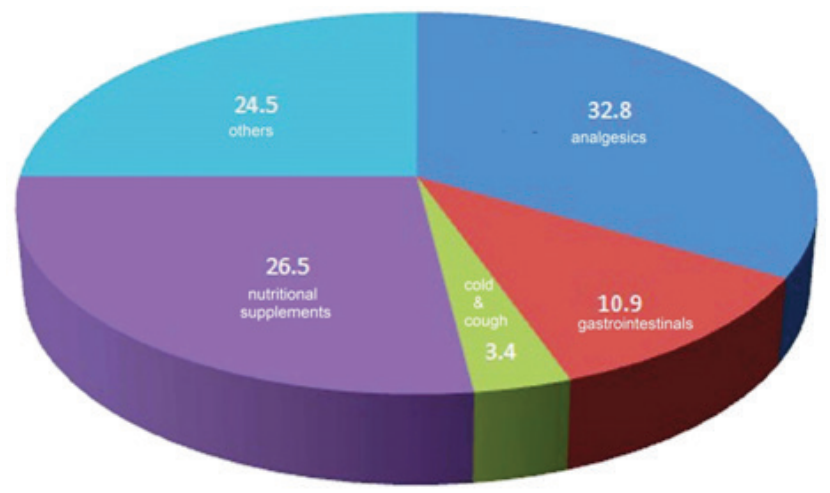

Figure 2: Categorization of OTC drugs as per the general indication

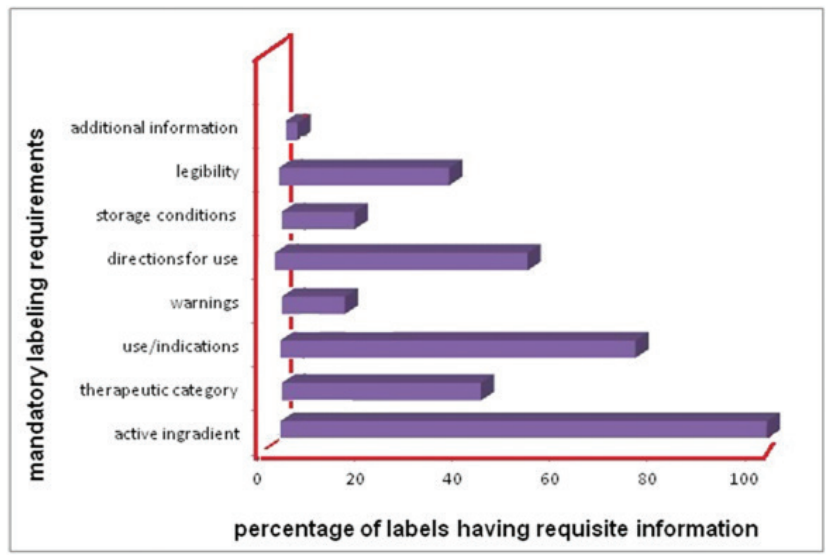

Figure 3: Percentage of labels having mandatory labelling requirements as per USFDA cosmetic act are listed in Table 2 that are product oriented while labeling requirement a are patient oriented as per US FDA guidelines. So the study was carried out with an objective to evaluate whether:

1. The labels of OTC medications have adequate information for the patients to make the proper self-medication.

2. Additional information is present or not on the patient package inserts wherever applicable.

3. The information provided is readable and can be clearly understood.

\section{EXPERIMENTAL METHODS}

A total of 100 OTC medicines were randomly collected from a pharmacy, covering various categories of medicines and various dosage forms like tablets, capsules, liquid orals and external preparations. The labels of these medicines were then assessed based on the "21 CFR 201.66" label guidelines provided by the United States Food and Drug Administration (US FDA) for OTC medicine labelling. The proposed labelling includes various components, and was studied as specified by Drug Facts standard labelling format, with the following results:

\section{(a) Label to include- Active ingredient along with its strength}

All the 100 labels evaluated fulfilled the given criteria as the name of active ingredients along with their potency/ strength was clearly marked on the packages.

\section{(b) Label to include-Therapeutic category/purpose}

The most common concern was the failure of the labels to identify the therapeutic class of drug. Almost $59 \%$ of the labels did not disclose the therapeutic category and some medications possessing the class didn't have any information regarding the pharmacokinetic parameters (e.g. Half life of drugs in case of long acting drugs should be mentioned otherwise may lead to toxicity).

\section{(c) Label to include-Uses /indications for which} medicine can be utilized

Although a significant percentage $(73 \%)$ mentioned the indications for the medicine. The topical medications and the nutritional supplements have been found to have better complied with the mandatory requirements $(85 \%)$ as compared to analgesics and gastrointestinal drugs $(63 \%)$. The indications were very broad, vague and almost 18\% labels lack the information regarding specific indications (first line treatment). 


\section{(d) Label to include-Warnings}

It includes the important aspects regarding safety issue of the product and the conditions which must be reported immediately. The labels should have proper information regarding common adverse effects, contraindications, precautions, over dosage, when it is appropriate to seek medical advice and special conditions like pregnancy \& breast-feeding.

\section{RESULTS}

1. $75 \%$ of the labels have been provided with a general warning.

2. $90 \%$ of the labels failed to enumerate the adverse effects of the medicine.

3. There was maximum percentage of labels $(86 \%)$ which did not state what is to be done in case of overdose

4. There was scarcely any label which provided information regarding usage in pregnancy and breastfeeding (4\%)

5. $87 \%$ of the labels didn't provide any information regarding contraindications of medicines.

6. $73 \%$ labels did not even advise to seek medical guidance.

\section{(e) Label to include-Directions for use}

This includes the dose that has to be given; the dosing interval and the dosage regimen for children. Almost half of the medicines (48\%) did not mention the amount to be used, while 34\% did not mention the dosing interval. Over $85 \%$ of the medicines did not state the maximum dose allowed. It was also observed that $64 \%$ of the medicines failed to specify the dose for children. Only one label included instructions for use in Devanagiri script.

\section{(f) Label to include -The product's inactive ingredients}

This makes the consumers avoid the ingredients that may cause an allergic reaction as it varies from person to person. A specific example is the failure of formulation to clearly mention the concentration of the alcohol in liquid formulations for children where small amount can cause severe damage.

None of the labels included the inactive ingredients (other than saying in some cases, the solvent/base used).

\section{(g) Label to include -Storage conditions}

Even though a large percentage (89\%) of the labels provided the storage conditions, maximum out of them were imprecise and difficult to understand. Nearly $85 \%$ of the labels were found without a specific temperature mention. Furthermore, the storage conditions and the terms used to describe them are not common and are not easily understood by a common man leading to huge confusion. E.g. It was mentioned to store the formulation at cool place, but no specific temperature range was indicated.

\section{(h) Label to include - Legibility to find out whether the label is easily readable}

Only $35 \%$ of the medicine labels were clearly legible as the font size was appropriate. $28 \%$ of drug labels could be read with much effort on the eyes while the remaining labels had a font size so small that they could be seen with the aid of magnifying glass.

\section{(i) Label to include-Additional information through patient package inserts:}

Patient package inserts are useful for providing additional information to the patient. Out of the 100 medicines examined, only 3 included a patient package insert. Many a times, secondary packaging of medicines is also given to the patient as additional protection for their medicines or as attractive packs. These secondary packages can also be used to convey valuable information to the patient. In $46 \%$ of the cases, a secondary package was found to be available to the patient, yet only 34\% of them gave more information on its label than the primary package. On the positive side, all the 100 labels did provide required details of manufacture and expiry of the medicines. These are also crucial requirements for medicine safety.

\section{DISCUSSION}

The study thus clearly revealed that there is limited space available on the primary package of the OTC medications to carry all the required information. In cases where there was a secondary package and a scope for providing additional information was available, yet the information was not provided. The use of primary package inserts was also not entertained at all, ignoring a very useful and easily accessible method to give all the necessary details to the patients for safe and efficacious use of the OTC medicines. The study also revealed that the required information provided on OTC medicine labels in India is usually quite insufficient for the patient to make a "responsible" decision for self-medication as it even not have the therapeutic category details and the dose that has to be taken (Figure 3). This causes a great concern regarding safe and effective use of OTC medications.

Indian Journal of Pharmacy Practice, Vol 9, Issue 3, Jul-Sep, 2016 


\section{CONCLUSION AND PRACTISE IMPLICATIONS}

There are no specific guidelines for OTC medications in India as laid by any regulating authority asking for an immediate need for a specific OTC category of medicines in India, with clear-cut laid down guidelines for their complete labelling. The label of OTC medicines should contain sufficient information, so that the patient gets sufficient information for the safe and effective use of OTC medications. There is an important need to considerably improve and organize the labelling of OTC medicines, so that they are simple, straight forward, and easy to read. The patient or the consumer can easily decide what the product is used for and what circumstances or medical conditions it should and should not be used.

\section{SUGGESTIONS}

There should be specific standards and provisions regarding the labels of the medications. There should be provision of minimum font size of the text for proper legibility to the patients. The labels should be designed and printed while considering the requirement of geriatric patients and the patients having somewhat impaired vision. The labels should also be printed in languages patients will comprehend. Patient leaflets should be used to give all details required in case the primary label is not having sufficient space. In case of developing nations like India the rural areas govern the maximum parameters, so it should be well kept in mind of the manufacturers and the packagers to design the package and label as per the local consumers. The labels have to become more patient and community oriented then to be product oriented. If critical information cannot be included on the primary label, suitable patient package inserts should be included with the medicine or on the secondary packages for the most efficient, safe, rational and ethical use of OTC medications. The study proves that the labelling of OTC medications till date in India is very much industry centred instead of patient centred and it should be corrected immediately in profit and service of the society.

\section{ACKNOWLEDGEMENT}

Prof. Devender Pathak, Principal, Pharmacy College Saifai, UPUMS, Saifai, Etawah 206130 for his support in conduct of the study

\section{CONFLICT OF INTEREST}

The authors declare no conflicts of interest.

\section{REFERENCES}

1. Betsy S, Richard H.R, William C, Lisa G, and Trina C. Physician-patient communication about over-the-counter medications. Social Sci. \& Med. 2001;53(3):357-69.

2. http://www.fda.gov/drugs/developmentapprovalprocess/howdrugs aredevelopedandapproved/approvalapplications/over-the-counterdrugs/ default.htm

3. Erin O. An overview of the US regulatory system for OTC products. Regulatory Rap porteur. 2013;10(3):4-9.

4. Dianne B, Theo R, Peter K, Elisabetta B. Over the counter medicines and the need for immediate action: a further evaluation of European Commission recommended wordings for communicating risk. Patient Educ. Couns. 2004;53(2): 129-34.

5. http://cdsco.nic.in/html/Drugs andCosmeticAct.pdf

6. http://www.fda.gov/drugs/resourcesforyou/consumers/ucm143547.htm

7. http://www.fda.gov/AboutFDA/CentersOffices/OfficeofMedicalProducts andTobacco/CDER/ucm106378.htm.

8. Elizabeth A, Sujit S.S, Caroline N, Rosa F.Y. Use/misuse of over-the-counter medications and associated adverse drug events among HIV-infected patients. Research in Soc. and Admin. Pharm. 2008; 4(3):292-301.

9. http://hosted.comm100.com/knowledgebase/Article_Print. aspx?id=151\&siteid=95439. "Indian OTC drugs market growing at a rate of 23\%" NCK Pharma solution private limited 2013.

10. Mala R. OTC Opportunity Knocking at the door. Interlink knowledge. 2011;9(1):14-7.

11. Dianne B, Theo R, Peter K, Elisabetta B. Over the counter medicines and the need for immediate action: a further evaluation of European Commission recommended wordings for communicating risk. Patient Educ. Couns. 2004;53(2):129-134

12. William H., Jerry A. Educating Patients About Their Medications: The Potential And Limitations Of Written Drug Information. Health Affair. 2007; 26(3):731-40.

13. http://www.faqs.org/health/topics/89/Drug-labeling.html. NCK Pharma solutions. "Drug labeling" 2014

14. Nagappa A.N, Doddapaneni S, Aluri R.C., Naik V. Quality of information on medicine labels and packages. Int. J. Commun. Pharm. 2012; 5(1): 6-14. 